\title{
ANALISA KINERJA MESIN REFRIGERASI RUMAH TANGGA DENGAN VARIASI REFRIGERAN
}

\author{
${ }^{1}$ Amrullah, ${ }^{2}$ Zuryati Djafar, ${ }^{3}$ Wahyu H. Piarah \\ ${ }^{1}$ Program Studi Perawatan dan Perbaikan Mesin, Politeknik Bosowa, Makassar 90245,Indonesia \\ 2,3 Jurusan Mesin, Fakultas Teknik, Universitas Hasanuddin, Makassar 90245,Indonesia \\ E-mail : amrullah.mansyur@yahoo.com ${ }^{1}$,yydjafar@yahoo.com ${ }^{2}$,wahyupiarah@yahoo.com ${ }^{3}$
}

\begin{abstract}
Abstrak
Komponen terpenting dalam mesin refrigerasi adalah refrigeran. Refrigeran menyerap panas dari satu lokasi dan membuangnya ke lokasi yang lain melalui mekanisme evaporasi dan kondensasi. Penelitian ini bertujuan untuk mengangkat suatu percobaan pengembangan mesin refrigerasi dengan menggunakan refrigeran yang berbeda sehingga dapat diamati kinerja kompresor, kinerja evaporator, COP dan diharapkan penelitian ini dapat memperlihatkan instalasi pengujian sebagai media pembelajaran dalam menerapkan prinsip kerja mesin refrigerasi. Metode penelitian yang dilakukan adalah eksperimental pada setting 8 mesin refrigerasi dengan melakukan pengambilan data untuk tekanan dan temperatur R-12 dan R-134a yang diukur pada saluran masuk dan keluar kompresor selama 300 menit. Penentuan nilai entalpi pada setiap titik dengan menggunakan program REFPROP. Penggunaan refrigeran yang berbeda pada suatu mesin refrigerasi menunjukkan bahwa refrigeran R134a lebih baik dibanding R-12. Hal ini dapat dilihat setelah 300 menit untuk R-134a, kinerja kompresor $29.4 \mathrm{~kJ} / \mathrm{kg}$, kinerja evaporator $144.5 \mathrm{~kJ} / \mathrm{kg}$, COP 4.9 sedangkan untuk R-12, kinerja kompresor $21.8 \mathrm{~kJ} / \mathrm{kg}$, kinerja evaporator $12.3 \mathrm{~kJ} / \mathrm{kg}$, COP 4.6 .
\end{abstract}

Kata kunci: refrigeran, evaporasi, kondensasi, COP

\begin{abstract}
The most important component in the refrigerator is the refrigerant. The refrigerant absorbs heat from one side and throw it to another side through the mechanism of evaporation and condensation. This research aims to develop a refrigeration machine using different refrigerants that can be observed with the performance of the compressor, evaporator performance and COP, and hoped this research can show the installation as a medium of learning in applying the working principle of refrigerator. The research method was experimental at setting 8 refrigeration machine with data collection for the pressure and temperature of $R-12$ and $R-134 a$ were measured at the compressor inlet and outlet for 300 minutes. Determining the value of the enthalpy at any point by using REFPROP program. The use of different refrigerants in a refrigeration machine indicates that the refrigerant $R-134 a$ better than $R$ 12. It can be seen after 300 minutes for $R-134 a$, compressor performance $29.4 \mathrm{~kJ} / \mathrm{kg}$, the performance of the evaporator is $144.5 \mathrm{~kJ} / \mathrm{kg}$, COP 4.9 while for $R-12$ compressor performance $21.8 \mathrm{~kJ} / \mathrm{kg}$, the performance of the evaporator is $12.3 \mathrm{~kJ} / \mathrm{kg}$, COP 4.6 .
\end{abstract}

Keywords: refrigerant, evaporation, condensation, COP

\section{Pendahuluan}

Penerapan teknik refrigerasi yang terbanyak adalah dalam proses pendinginan yaitu untuk pengkondisian udara baik refrigerasi industri maupun rumah tangga yang meliputi pemrosesan, pengawetan makanan, penyerapan kalor dari bahan-bahan kimia, perminyakan dan industri petrokimia.
Refrigerasi adalah proses penurunan temperatur dari suatu zat hingga temperatur zat tersebut lebih rendah dari temperatur lingkungannya, dimana refrigerasi ini bekerja dengan membentuk suatu siklus. Dengan adanya siklus refrigerasi ini, telah merintis pembuatan mesin pendingin atau refrigerator dosmetik untuk keperluan rumah tangga atau yang lebih dikenal dengan kulkas.

Refrigerasi mempunyai hubungan yang erat dengan pendinginan, dimana pendinginan tersebut dapat diartikan sebagai proses pelepasan kalor dari suatu zat 
yang akan didinginkan. Pendinginan dilakukan sesuai dengan tujuan masing-masing orang yang akan melakukan proses pendinginan tersebut. Namun secara umum pendinginan bertujuan untuk membuang panas dari suatu zat sehingga temperaturnya menjadi lebih rendah, mengubah wujud suatu zat seperti mengubah air menjadi es serta mempertahankan temperatur dari zat tersebut.

Komponen terpenting dalam mesin refrigerasi adalah refrigeran. Refrigeran adalah fliuida kerja yang bersirkulasi dalam siklus refrigerasi karena menggunakan efek pendinginan dan pemanasan pada mesin refrigerasi dengan menyerap panas dari satu lokasi dan membuangnya ke lokasi yang lain melalui mekanisme evaporasi dan kondensasi. Meskipun pada dasarnya refrigerasi merupakan salah satu penyebab timbulnya masalah kontemporer terhadap adanya pemanasan global (global warning) [1].

Ketika mendesain suatu sistem refrigerasi, perlu diperhatikan beberapa refrigeran yang akan digunakan seperti chlorofluorocarbons (CFCs), amonia, hidrokarbon (propane, ethane, ethylene), karbodioksida, udara dan bahkan air (pada aplikasi diatas titik beku). Pemilihan refrigeran yang baik hendaknya berdasarkan kondisinya, misalnya R-11, R-12, R-22, R-134a dan R502 yang dijual banyak di pasaran [2].

Bagian penting lain dalam menganalisis sistemsistem termal adalah penentuan sifat-sifat termodinamika. Suatu sifat adalah setiap karakteristik atau ciri dari bahan yang dapat dijajaki secara kuantitatif, seperti suhu, tekanan dan rapat massa. Kerja dan perpindahan kalor dapat dijajaki dalam hal perubahan sifat-sifatnya, tetapi keduanya bukan merupakan sifat itu sendiri. Suatu sifat adalah segala sesuatu yang dimiliki oleh bahan. Kerja dan perpindahan kalor adalah hal yang dilakukan terhadap suatu sistem sehingga terjadi perubahan pada sifat-sifatnya. Kerja dan kalor hanya dapat diukur hanya pada pembatas sistem dan jumlah energi yang dipindahkan tergantung pada cara terjadinya perubahan [3].

Proses pemanasan lanjut yang terjadi pada siklus kompresi uap disebabkan karena adanya proses perpindahan kalor yang terjadi pada saat saluran penghubung antara evaporator dan kompresor. Proses pendinginan lanjut yang terjadi pada siklus kompresi uap disebabkan karena adanya perpindahan kalor yang terjadi pada saluran penghubung antara kondensor dan pipa kapiler [4].

Beban pendinginan sebenarnya adalah jumlah panas yang dipindahkan oleh sistem pengkondisian udara setiap waktu. Beban pendinginan terdiri atas panas yang berasal dari ruang dan tambahan panas [5].

Siklus refrigerasi dan analisa kinerja refrigeran pada mesin refrigerasi dapat diamati pada skema instalasi mesin refrigerasi seperti yang ditunjukkan pada gambar 1.

\section{Evaporasi}

Proses evaporasi terjadi pada evaporator atau penguap yang digunakan pada mesin refrigerasi berbentuk pipa bersirip plat. Tekanan cairan refrigeran yang diturunkan pada katup ekspansi didistribusikan secara merata kedalam evaporator oleh refrigeran. Refrigeran akan menguap dan menyerap kalor dari udara ruangan yang dialirkan melalui permukaan luar pipa evaporator. Jadi cairan refrigeran diuapkan secara berangsur-angsur karena menerima kalor sebanyak kalor laten penguapan selama mengalir di dalam setiap pipa dari koil evaporator. Pada gambar 2 dan 3, evaporasi dapat dilihat pada proses 4-1 sehingga kinerja evaporator dapat diketahui dari selisih antara entalpi pada titik 1 dan titik 4.

$$
\mathbf{q}_{\mathrm{e}}=\mathbf{h}_{\mathbf{1}}-\mathbf{h}_{4}
$$

\section{Kompresi}

Bila suatu gas dikompresi berarti ada energi mekanik yang diberikan dari luar kepada gas. Energi tersebut diubah menjadi energi panas sehingga temperatur gas akan naik jika tekanan semakin tinggi [6]. Proses kompresi yang terjadi pada kompresor menyebabkan naiknya tekanan refrigeran sehingga memudahkan pencairannya kembali. Energi yang diperlukan untuk kompresi diberikan oleh motor listrik yang menggerakkan kompresor. Dalam proses kompresi, energi diberikan kedalam uap refrigeran. Pada gambar 2 dan 3, kompresi dapat dilihat pada proses 1-2 sehingga kinerja kompresor dapat diketahui dari selisih entalpi titik 2 dan titik 1.

$$
\mathbf{q}_{\mathbf{w}}=\mathbf{h}_{2}-\mathbf{h}_{1}
$$

\section{Kondensasi}

Uap refrigeran yang bertekanan dan bertemperatur tinggi pada akhir kompresi dapat dengan mudah didinginkan dengan udara pendingin yang ada pada temperatur normal. Dengan kata lain, uap refrigeran menyerahkan panasnya (kalor laten pengembunan) pada udara pendingin didalam kondensor sehingga mengembun dan menjadi cair. Karena udara pendingin menyerap udara dari refrigeran, maka udara akan menjadi panas pada saat keluar dari kondensor. Pada gambar 2 dan 3, kondensasi dapat dilihat pada proses 2-3 sehingga kinerja kondensor dapat diketahui dari selisih antara entalpi pada titik 2 dan titik 3 .

$\mathbf{q}_{\mathbf{c}}=\mathbf{h}_{2}-\mathbf{h}_{3}$

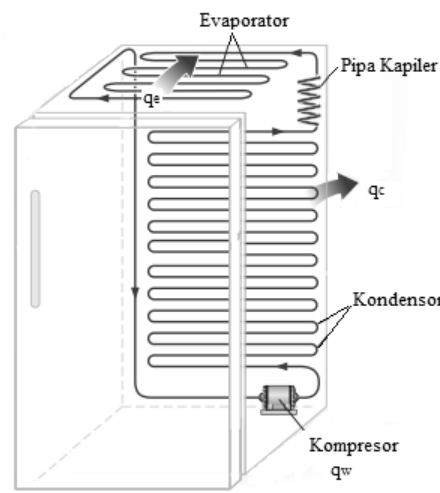

Gambar 1. Siklus refrigerasi pada mesin refrigerasi 


\section{Ekspansi}

Untuk menurunkan tekanan dari refrigeran cair yang dicairkan didalam kondensor supaya dapat mudah menguap, maka dipergunakan katup ekspansi atau pipa kapiler. Cairan refrigeran dari katup ekspansi kemudian mengalir kedalam evaporator, tekanannya turun dan menerima kalor penguapan dari udara, sehingga mengalami penguapan secara berangsur-angsur. Selanjutnya, proses siklus tersebut di atas terjadi secara berulang-ulang. Pada gambar 2 dan 3, proses ekspansi dapat dilihat pada proses 3-4.

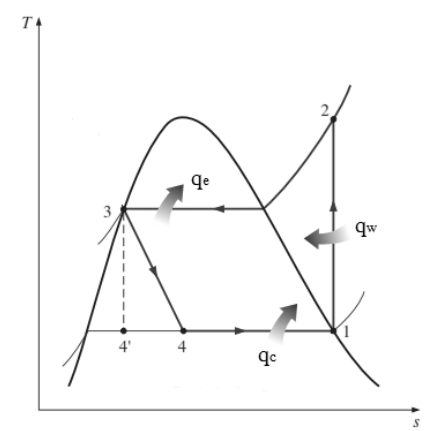

Gambar 2. Diagram T-s siklus refrigerasi

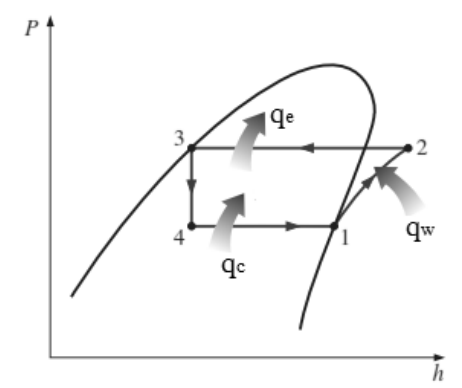

Gambar 3. Diagram P-h siklus refrigerasi

\section{Coefficient of Performance (COP)}

Koefisien kinerja atau COP berhubungan dengan kapasitas pendinginan dan daya yang diperlukan dan menunjukkan konsumsi daya keseluruhan untuk beban yang diinginkan. Nilai COP yang tinggi menunjukkan konsumsi energi rendah untuk penyerapan daya pendinginan ruang yang sama untuk didinginkan. Nilai $\mathrm{COP}$ dapat diketahui dari perbandingan antara refrigerasi bermanfaat terhadap kerja bersih.

$$
\mathrm{COP}=\frac{\mathrm{q}_{\mathbf{e}}}{\mathrm{q}_{\mathrm{w}}}
$$

Penelitian ini bertujuan untuk mengangkat suatu percobaan pengembangan mesin refrigerasi dengan menggunakan refrigeran yang berbeda sehingga dapat diamati kinerja kompresor, kinerja evaporator dan COP.

\section{METODE}

Metode penelitian yang dilakukan adalah eksperimental pada setting 8 mesin refrigerasi dengan melakukan pengambilan data untuk tekanan dan temperatur R-12 dan R-134a yang diukur pada saluran masuk dan keluar kompresor selama 300 menit. Penentuan nilai entalpi pada setiap titik dengan menggunakan program REFPROP (REFerence fluid PROPerties). Program ini digunakan untuk menghitung sifat termodinamika dan transport dari suatu fluida dan campurannya [7].

Pengolahan data dilakukan untuk menentukan kinerja dari komponen mesin refrigerasi dan nilai COP.

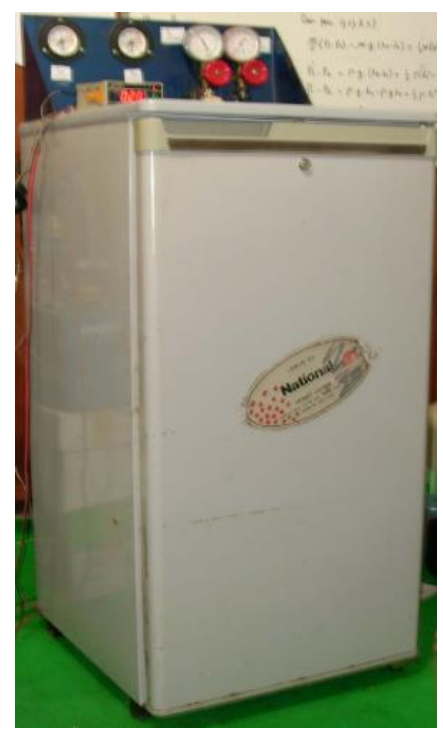

Gambar 4. Instalasi alat pengujian

\section{HASIL DAN PEMBahasan}

Pengujian pada mesin refrigerasi telah dilakukan dengan pengukuran temperatur dan tekanan dengan R-12 dan R-134a sebagai fluida kerja. Data hasil pengujian ditampilkan dalam tabel 1 dan tabel 2.

\begin{tabular}{|c|c|c|c|c|}
\hline $\begin{array}{c}\text { Waktu } \\
(\mathbf{s})\end{array}$ & $\begin{array}{c}\mathbf{q} \mathbf{e} \\
(\mathbf{k J} / \mathbf{k g})\end{array}$ & $\begin{array}{c}\mathbf{q}_{\mathbf{w}} \\
(\mathbf{k J} / \mathbf{k g})\end{array}$ & $\begin{array}{c}\mathbf{q}_{\mathbf{c}} \\
(\mathbf{k J} / \mathbf{k g})\end{array}$ & $\mathbf{C O P}$ \\
\hline 30 & 95.4 & 21.5 & 117.5 & 4.4 \\
\hline 60 & 96.5 & 21.6 & 119.6 & 4.5 \\
\hline 90 & 97.9 & 21.7 & 121 & 4.5 \\
\hline 120 & 99.4 & 21.7 & 121.7 & 4.6 \\
\hline 150 & 99.4 & 21.7 & 121.7 & 4.6 \\
\hline 180 & 100.5 & 21.8 & 122.3 & 4.6 \\
\hline 210 & 100.5 & 21.8 & 122.3 & 4.6 \\
\hline 240 & 100.5 & 21.8 & 122.3 & 4.6 \\
\hline 270 & 100.5 & 21.8 & 122.3 & 4.6 \\
\hline 300 & 100.5 & 21.8 & 122.3 & 4.6 \\
\hline
\end{tabular}

Tabel 1. Kinerja evaporator, kompresor, kondensor dan COP menggunakan R-12 


\begin{tabular}{|c|c|c|c|c|}
\hline $\begin{array}{c}\text { Waktu } \\
(\mathbf{s})\end{array}$ & $\begin{array}{c}\mathbf{q} \mathbf{e} \\
(\mathbf{k J} / \mathbf{k g})\end{array}$ & $\begin{array}{c}\mathbf{q}_{\mathbf{w}} \\
(\mathbf{k J} / \mathbf{k g})\end{array}$ & $\begin{array}{c}\mathbf{q} \mathbf{c} \\
(\mathbf{k J} / \mathbf{k g})\end{array}$ & $\mathbf{C O P}$ \\
\hline 30 & 138.8 & 31.4 & 169.9 & 4.4 \\
\hline 60 & 141.8 & 30.4 & 169.6 & 4.7 \\
\hline 90 & 143.5 & 30.4 & 173.1 & 4.7 \\
\hline 120 & 143.4 & 30.2 & 173.6 & 4.7 \\
\hline 150 & 143.4 & 30.2 & 173.6 & 4.7 \\
\hline 180 & 144.5 & 29.4 & 173.9 & 4.9 \\
\hline 210 & 144.5 & 29.4 & 173.9 & 4.9 \\
\hline 240 & 144.5 & 29.4 & 173.9 & 4.9 \\
\hline 270 & 144.5 & 29.4 & 173.9 & 4.9 \\
\hline 300 & 144.5 & 29.4 & 173.9 & 4.9 \\
\hline
\end{tabular}

Tabel 2. Kinerja evaporator, kompresor, kondensor dan COP menggunakan R-134a

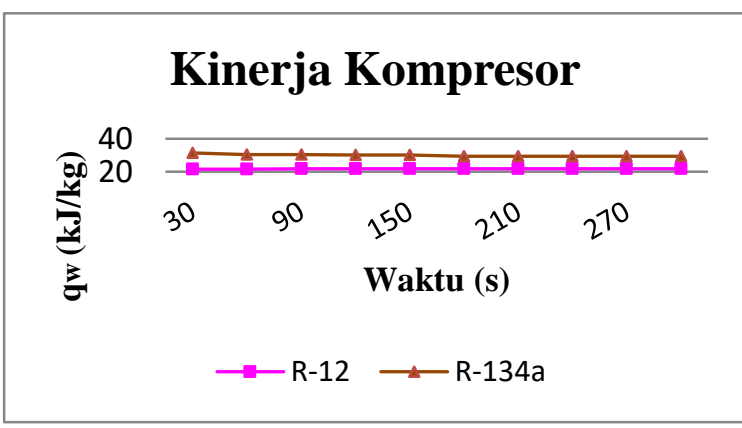

Gambar 5. Kinerja kompresor selama 300 menit

Kinerja kompresor pada mesin refrigerasi merupakan selisih entalpi yang dapat diketahui dari temperatur dan tekanan yang diukur pada kondisi masuk dan keluar kompresor. Bila suatu gas dikompresi berarti ada energi mekanik dari luar yang diberikan kepada gas. Energi tersebut diubah menjadi energi panas sehingga temperatur gas akan naik jika tekanan semakin tinggi [4]. Pada gambar 5, nilai kalor $\left(\mathrm{q}_{\mathrm{w}}\right)$ untuk R-134a lebih tinggi dibanding nilai kalor $\left(\mathrm{q}_{\mathrm{w}}\right)$ untuk R-12. Hal tersebut menunjukkan bahwa Refrigeran R-134a lebih baik dari $\mathrm{R}-12$.

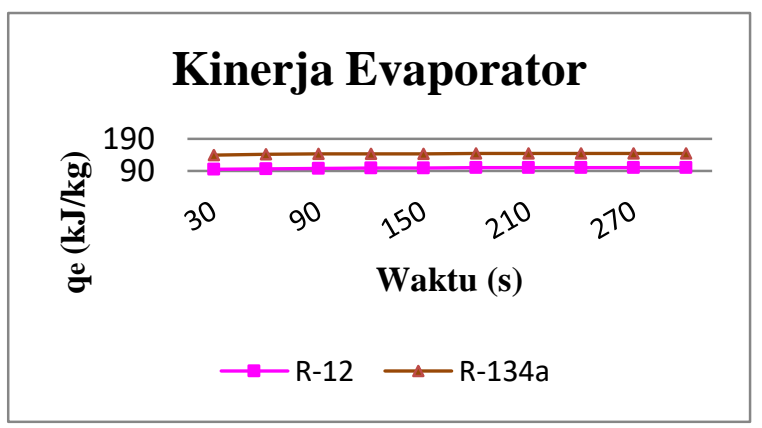

Gambar 6. Kinerja evaporator selama 300 menit

Kinerja evaporator pada mesin refrigerasi dapat diketahui dengan menentukan selisih dari entalpi pada kondisi masuk kompresor dan masuk evaporator. Seperti yang ditunjukkan pada gambar 6, nilai qe untuk R134a lebih tinggi dibanding R12. Hal tersebut menunjukkan R134a memiliki nilai kalor yang lebih baik dibanding R12.

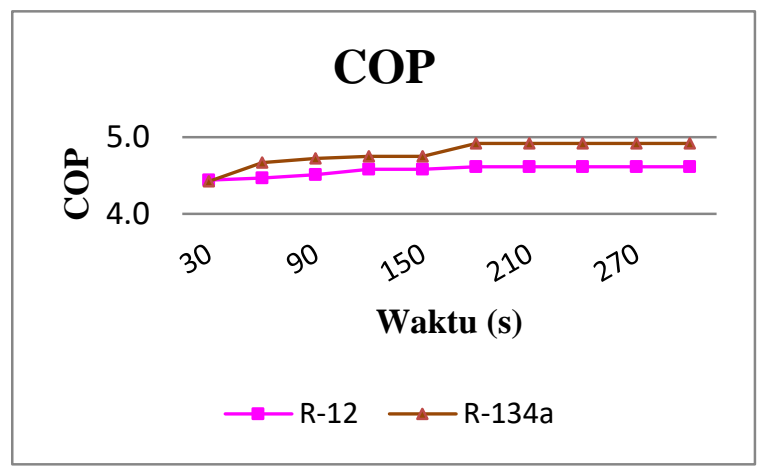

Gambar 7. COP selama 300 menit

Pada gambar 7 ditunjukkan nilai COP untuk R-134a dan R-12 mengalami kenaikan selama 300 menit. Nilai COP pada R-134a lebih tinggi dibanding COP pada R-12. Hal ini menunjukkan bahwa R-134a mengkonsumsi energi yang rendah dibanding penggunaan R-12 untuk penyerapan daya pendinginan ruang yang sama untuk didinginkan. Penggantian refrigeran pada sistem pendingin dengan instalasi yang sama dapat memberikan hasil performansi yang berbeda, hal ini disebabkan karena perbedaan masa jenis refrigeran sehingga laju aliran massa refrigeran juga berbeda.

\section{PENUTUP}

\section{Kesimpulan}

Penggunaan refrigeran yang berbeda pada suatu mesin refrigerasi menunjukkan bahwa refrigeran R-134a lebih baik dibanding R-12. Hal ini dapat dilihat setelah 300 menit untuk R-134a, kinerja kompresor $29.4 \mathrm{~kJ} / \mathrm{kg}$, kinerja evaporator $144.5 \mathrm{~kJ} / \mathrm{kg}$, COP 4.9 sedangkan untuk $\mathrm{R}-12$, kinerja kompresor $21.8 \mathrm{~kJ} / \mathrm{kg}$, kinerja evaporator $12.3 \mathrm{~kJ} / \mathrm{kg}$, COP 4.6 .

\section{Saran}

Diharapkan penelitian ini dapat memperlihatkan instalasi pengujian sebagai media pembelajaran dalam menerapkan prinsip kerja mesin refrigerasi.

\section{Nomenklatur}

$\begin{array}{ll}\mathrm{q}_{\mathrm{e}}= & \text { Kinerja Evaporator }[\mathrm{kJ} / \mathrm{kg}] \\ \mathrm{q}_{\mathrm{w}}= & \text { Kinerja Kompresor }[\mathrm{kJ} / \mathrm{kg}] \\ \mathrm{q}_{\mathrm{c}}= & \text { Kinerja Kondensor }[\mathrm{kJ} / \mathrm{kg}] \\ \mathrm{h}_{1}=\text { Entalpi pada titik } 1 \text { (masuk kompresor) }[\mathrm{kJ} / \mathrm{kg}] \\ \mathrm{h}_{2}=\text { Entalpi pada titik } 2 \text { (masuk kondensor) }[\mathrm{kJ} / \mathrm{kg}] \\ \mathrm{h}_{3}=\text { Entalpi pada titik } 3 \text { (masuk katup ekspansi) } \\ \\ \mathrm{h}_{4}=\text { Entalpi pada titik } 4 \text { (masuk evaporator) }[\mathrm{kJ} / \mathrm{kg}\end{array}$




\section{DAFTAR PUSTAKA}

[1] Alfons E.P., dkk., Analisis Pengaruh Variasi Massa LPG sebagai Refrigeran terhadap Prestasi Kerja dari Lemari Es. Jurnal ROTOR, Volume 6 Nomor 1, Januari 2013.pp.1.

[2] Cengel. Yunus A and Michael A Boles, Thermodynamics: An Engineering Approach 5th edition.: McGraw-Hill, 2006.

[3] Stoecker.WJ, Refrigeran dan PengkondisianUdara. Edisi kedua, Erlangga, Jakarta,1992.

[4] Lothar P, Freezer dengan Daya 1/6 PK dan Panjang Pipa Kapiler $150 \mathrm{~cm}$, Jurusan Teknik Mesin Universitas Sanata Darma,Yogyakarta,2015.pp.71.

[5] M.Rizal, dkk, Pengaruh Variasi Beban Pendinginterhadap Prestasi Kerja Mesin Pendingin dengan Refrigeran R12 dan LPG, Jurnal ROTOR Volume 6 No.1, Januari 2013.pp.2.

[6] Sularso, Pompa dan Kompresor ,PT.Pradnys Paramita. Jakarta, 2006.

[7] Eric W. Lemmon, dkk, NIST Reference Fluid Thermodynamic and Transport PropertiesREFPRO. U.S. Department of Commerce, Maryland, 2010. 